\title{
STREAM FLOW AND RAINFALL TREND ANALYSIS OF THE SSEZIBWA CATCHMENT
}

Musiime Enos Bahati ${ }^{1 *}$, Dr. Lawal Abdul Qayoom Tunji ${ }^{2}$, Dr. Peter Benjamin Aina ${ }^{3}$, Matovu Solomon ${ }^{4}$

1. Post graduate Student, Department of Civil Engineering, Kampala International University, P.O. Box 20000, Kampala, Uganda

2. Dean School of Engineering, Kampala International University, P.O. Box 20000, Kampala, Uganda

3. Head of Department Physical Sciences, Kampala International University, P.O. Box 20000, Kampala, Uganda

4. Deputy Director Quality Assurance, Kampala International University, P.O. Box 20000, Kampala, Uganda

\begin{abstract}
The study focused on two climatic variables i.e. precipitation and stream flow for analysing change in trend of rainfall for the River Ssezibwa Catchment area and stream flow of River Ssezibwa. This Catchment is found in the districts of Mukono and Buikwe in Uganda. In this area agriculture is majorly dependent on rainfall and irrigation on a small scale. However, rainfall occurrence has become unpredictable over the past few years as result of the changes in patterns of weather. This has caused severe effects on the agricultural cropping system as well as caused negative effects on the natural water resources. Stream flow data of 57 years (1960 - 2017) and rainfall data for 35 years $(1982$ - 2017) on a daily basis was analysed to find out the trend and detect change point. Trend analysis was done by using the non-parametric analysis while the change point detection was carried out by using the Pettit test (1979).Magnitude of trend for the time series data was carried out using Sen's Slope estimator and Mann - Kendall test was done to determine the trend. Results from the statistical analysis highlighted that; for streamflow the trend was generally positive and change point detected to be in the year 2000 while for rainfall data analysis indicated that the trend was predominantly negative and change point was in the year 1998).
\end{abstract}

Key words: Streamflow trend, Rainfall trend, Mann - Kendall trend, Pettit test, Sen's Slope Estimator, Trend analysis and Change point

\subsection{Introduction}

World over water resources have become essential for planning and development of most urban areas. For sustainable development of water resources related projects such as water supply for urban area, agricultural and food production, drainage and flood prediction, etc.

Rainfall is one of the major constituents of the hydrological cycle and also a major source of fresh water on earth by principle hence most of the extreme events of precipitation are directly linked to the magnitude and frequency of occurrence of rainfall. If the rainfall is too high as compared to the infiltration capacity of the soil, this results in high rates of runoff, landslides, and floods. Therefore, it is important to have knowledge of the maximum and distribution of precipitation over a catchment area. (Bhardwaj, 2015) 
Statistical Analysis of rainfall data and related studies is very significant in hydrology and water resources assessment. This is important for planning and maintenance of water resources related infrastructure (Norhan Abd Rahman, 2016). It is important to also note that for proper planning for extreme weather-related emergencies, the design of hydraulic and other engineering structures, and proper management of reservoirs all rely on the knowledge of the amount and frequency of the extreme environmental events.

Variability of rainfall has been believed to occur as a result of climate change. It is predicted that availability of freshwater is going to reduce in future because of the increasing global warming. Climate change is mainly brought about by the human factors, this evidenced by the rapid change in land use due to reclamation of forests and wetlands in search for more land agriculture and settlement. This is brought about the increasing human population.

The changes in rainfall trends directly affects the water resources and other human activities that are dependent on rainfall like agriculture. Uganda is mainly an agricultural nation, $65 \%$ of its labour force is employed in agricultural related activities and also agriculture contributes about $21 \%$ of Uganda's GDP. (UBOS, 2017)

This study is mainly focused on trend analysis and change point detection on both streamflow of River Ssezibwa and rainfall data of the Ssezibwa catchment area.

\subsection{The Study Area}

The study area is the Catchment of River Sezbwa, it is located in south Central part of Uganda, in East Africa. The Sezibwa river catchment is comprised of areas of Buikwe, Mukono, Kayunga and Nakasongola. The water shed of River Sezibwa are the wetlands between Lake Victoria and Lake Kyoga and it flows starting from Buikwe district near a town known as Ngogwe with coordinates: Latitude 0.2700; Longitude: 33.0050, then through Mukono district and empty into Lake Kyoga in Kayunga District at a town of Galilaya, with coordinates: Latitude: 1.3700; Longitude: 32.8150.

The main economic activity carried out by the people in this area is Agriculture. However, some industries have been coming up of recent and also commercial towns have also developed in this area over years. As a result in the recent years the land use patterns have changed.

\subsection{Studies on Trend Analysis}

One of the current serious global challenge that is affecting most of the sectors in the world is climate change. This is a serious challenge to the realisation of sustainable development in most regions of the world, developing countries being the most affected. Climate variability affects the development of agriculture, economic activities, and infrastructure. (IPCC, 2014)

In climate change related studies, hydrological variables are very important parameters and indicators for climate change. This is because climate and hydrology are related subjects, hence hydrological variables can be used to indicate changes in climate. It is believed that when climate change occurs, then there is an effect on the hydrologic variables.

In a research carried out on the Upper Blue Nile River, the findings indicated that the stream flows are projected to increase by $26 \%$ in the period between 2010 and 2039, then also a decrease there after by $10 \%$ between 2070 and 2099. This is mainly attributed to the change in land use/cover as a result of increased modification of natural vegetation into agricultural crop land (Meron Teferi Taye, 2015). 
According to recent findings, it is believed that rainfall is likely to be concentrated into intense storms as a result of climate change. Therefore, there is need to carryout proper and appropriate assessment of the current climate variability situation, the disaster likely to arise and the effect on the construction and design of hydraulic structures in order to cope with the huge damage of these extreme events ( Hemin Sun et al, 2017).

Donald $\mathrm{H}$. Burn et al, proposed that stream variables be used for climate change related studies because of their spatially integrated hydrologic response that they provide. They also asserted that timing and duration of the hydrologic events should be included. Trend analysis results can be used to determine whether the time series for hydrologic variables show a number of trends that are greater than the number that is expected to occur by chance (Donald H. Burn, 2001).

Sathish et al used the Thomas - Fiering model for predicting the hydrology time series on rivers. The recommended that more focus should be put on the use of this model in the field of applied hydrology research (Babu, 2017).

Climate change impact on maximum flow values and variations can be easily investigated by performing a trend and risk analysis. Yenigun $\mathrm{K}$ et al, investigated the maximum flow trends and their impact on risk levels of spillways and found that the entire risk values reduced (remained stable) except for one dam where there was a slight increase. They attributed this scenario to the effect of climate change on precipitation (Yenigu et al, 2016).

There is a current growing debate among scientists and engineers that return periods of storms are increasingly becoming shorter as a result of climate change and global warming. Hence thorough study is needed in this area of hydrology and part of the studies needed is frequency analysis of rainfall, however, frequency analysis works only when there is a fixed rainfall duration. Rainfall can be study for different durations, say 1 hour, 24 hours, can be months to years (Chulsang Yoo et at, 2015). The design criteria of drainage system is mostly based on the return period of extreme storms.

\subsection{Materials and Methods}

Daily rainfall data for the study area recorded for the thirty five years $(1982$ - 2017) was purchased from the Uganda National Meteorological Authority. Two stations were considered since they were the only ones available to provide data for that period of time.

Daily streamflow data for Sezibwa River was obtained from the Department of Water Resources Management, Ministry of Water and Environment. The station from which the data was obtained was from a river gauge at Kayunga $(0: 56: 33 \mathrm{~N} ; 32: 48: 6 \mathrm{E})$ with station number 82255

\subsection{Trend Analysis}

The approach of trend analysis that was applied was the Mann - Kendall (MK) (Kendall, 1955) non-parametric test. In this method of analysis a null hypothesis that there is no trend in the data series was made. The autocorrelation effect was removed by computation of Sen's slope. Sen's slope estimator is non-parametric method that was developed by Sen (1968) to compute the true slope if in a time series there exists a linear trend (K. Drapela and I. Drapelova, 2011).

Mann - Kendall test statistic $\mathrm{S}$ is given by 


$$
S=\sum_{k=1}^{n-1} \sum_{j=k+1}^{n} \operatorname{Sgn}\left(X_{j}-X_{k}\right)
$$

Where the $\mathrm{S}$ denotes the MK test; $\mathrm{x}$ is the target variable; $\mathrm{n}$ is the length of the data set (sample size), and

$$
\operatorname{Sgn}\left(x_{j}-x_{k}\right)=\left\{\begin{array}{l}
+1 \text { if } x_{j}-x_{k}>0 \\
0 \text { if } x_{j}-x_{k}=0 \\
-1 \text { if } x_{j}-x_{k}<0
\end{array}\right.
$$

Mann and Kendall (Kendall, 1955)have documented that when $\mathrm{n} \geq 8$, then statistic $\mathrm{S}$ is approximately normally distributed with the mean and the variance as follows;

$$
\begin{gathered}
E(s)=0 \\
v(s)=\frac{n(n-1)(2 n-5)-\sum_{p=1}^{q} t_{p}\left(t_{p}-1\right)\left(2 t_{p}+5\right)}{18}
\end{gathered}
$$

Where

$\mathrm{n}=$ number of data

$t_{p}=$ the number of ties for $p^{\text {th }}$ value (number of data in the $p^{\text {th }}$ group)

$\mathrm{q}=$ the number of tied values (number of groups with equal values/ties)

The standardised Mann-Kendall test statistic $\mathrm{Z}_{\mathrm{MK}}$ will be computed by

$$
\mathrm{Z}=\left\{\begin{array}{l}
\frac{s-1}{\sqrt{\operatorname{var}(s)}} \text { for } s>0 \\
0 \text { for } s=0 \\
\frac{s+1}{\sqrt{\operatorname{var}(s)}} \text { for } s<0
\end{array}\right.
$$

The standardised MK statistic $\mathrm{Z}$ follows the standard normal distribution with mean of zero and variance of one. If $|Z|>Z_{1-\alpha / z}$, the null hypothesis $\left(\mathrm{H}_{0}\right)$ is rejected at a significance level of $\alpha$. Significance level of $95 \%$ was used to test for the null hypothesis that there's no trend. The $\mathrm{Z}$ - value can either be positive for increasing trend or negative for a decreasing trend.

Sen's slope estimator formula is written as follows;

$$
d_{k}=\frac{x_{j}-x_{k}}{j-k}
$$

For $(1 \leq k<j \leq n)$, where $\mathrm{d}$ is the slope, $\mathrm{x}$ denotes the variable, $\mathrm{n}$ is the number of data, and $\mathrm{k}, \mathrm{j}$ are indices. 
Sen's slope is calculated as a median from all slopes: $b=$ median $d_{k}$. For each time step $t$ the intercept is computed using the formula below;

$$
a_{t}=x_{t}-b t
$$

The corresponding intercept is well the median of all intercepts. The upper ad lower confidence limits for Sen's slope can also be computed using the above function.

\subsection{Change Point Detection}

Change point detection using the Pettitt test (1979) procedure was carried out to identify times when change occurred in the time series. This approach is applied to detect a single change point in hydrological time series with continuous data. The non-parametric statistic is defined as:

$$
\begin{aligned}
& K_{T}=\max \left|U_{t, T}\right| \\
& T=\arg \max (U)
\end{aligned}
$$

Where

$$
\begin{aligned}
& U_{t, T}=\sum_{i=1}^{t} \sum_{j=t+1}^{T} \operatorname{sgn}\left(x_{i}-x_{j}\right) \\
& \operatorname{sgn}(x-x)=\left\{\begin{array}{c}
+1, x_{j}>x_{i} \\
0, x_{j}=x_{i} \\
-1, x_{j}<x_{i}
\end{array}\right.
\end{aligned}
$$

$\mathrm{K}_{\mathrm{T}}$ is the location of the change point in the time series, as long as the statistic is significant. $\mathrm{T}$ is the change point; $\mathrm{x}$ is the target variable.

\subsection{Results and Discussion}

Trend analysis was carried out on both rainfall data and stream flows of the catchment area. Data from two rainfall recording stations was used for analysis while stream flow data for River Sezibwa was used. 


\subsection{Trend Analysis of Stream flow}

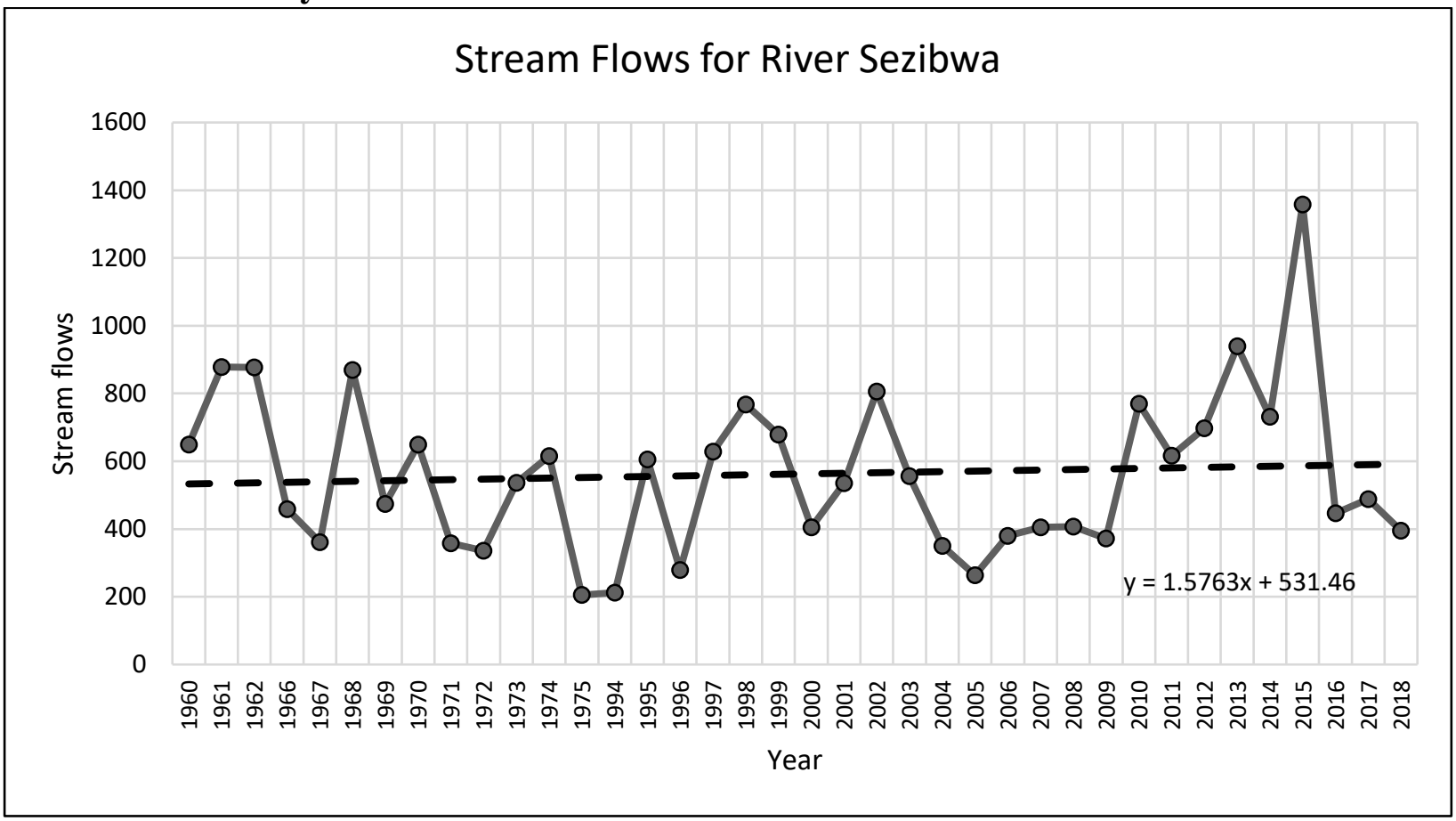

Figure 1: Annual precipitation time series and corresponding interpolated regression line. In this picture, the time series (from 1960 to 2017) is presented.

The analysis in figure (1) shows the trend in the stream flows from 1960 to 2017 on river in Mukono District, Uganda. The plot also includes a superimposed regression line to portray the overall variation in the stream flows over the years. The data indicates that on average, there has a slope of about $1.5763 \mathrm{~m}^{3} / \mathrm{s}$ annually.

Table 4.1: Mann - Kendall Trend test Results

\begin{tabular}{|l|l|l|l|l|}
\hline Score & Var(score) & Denominator & Tau & 2-sided pvalue \\
\hline-7466 & 7970064 & 85899.5 & -0.0869 & 0.0081877 \\
\hline \multicolumn{5}{|l|}{ Seasonally Adjusted MK trend test Results } \\
\hline-618 & 57450 & 6964.998 & -0.0887 & 0.0099271 \\
\hline
\end{tabular}

Under the null hypothesis that there exist no trend, the Mann-Kendall trend test is commonly used to determine if a trend exists, and can handle seasonal patterns within the data. Under the null hypothesis that there exists no trend in the overall stream flows, the Mann-Kendall trend test results (shown in table 4.1) indicates that there exists a trend in the overall stream flows (MK $=-7466$, tau $=-0.0869$, P-value $<0.05)$. The results of the seasonally adjusted MannKendall trend test also reports that a trend exists in the stream flows $(\mathrm{MK}=-7466$, tau $=-$ 0.0887 , P-value < 0.05). The results for trend are not any different even after adjusting for seasonality in the precipitation amounts for the period of study. 
The Pettitt's test for single change-point detection indicate that change in the trend occurred in the year $2000(\mathrm{~K}=190, \mathrm{P}$-value < 0.05) further indicating that there was a change in the overall stream flows.

\subsection{Trend Analysis of Rainfall}

Table 4.2: Trend analysis test results

Statistical analysis of the daily rainfall data was carried out to determine the values of statistical variables (mean, median, standard deviation, etc) of rainfall in the catchment area.

\begin{tabular}{|l|l|l|l|l|l|l|l|l|l|l|}
\hline $\begin{array}{l}\text { TIME- } \\
\text { SERIES }\end{array}$ & MEAN & MEDIAN & MIN & MAX & SD & Beta & $\begin{array}{l}\text { Mann- } \\
\text { Kendall }\end{array}$ & Sig. & $\begin{array}{l}\text { Sen's } \\
\text { slope }\end{array}$ & $\begin{array}{l}\text { Z- } \\
\text { score }\end{array}$ \\
\hline JANUARY & 2.61 & 2.31 & 0.00 & 65.80 & 5.26 & -3.46 & -188 & 0.014 & -3.418 & -2.446 \\
\hline FEBRUARY & 2.81 & 1.11 & 0.00 & 39.33 & 4.34 & -2.98 & -148 & 0.055 & -2.350 & -1.923 \\
\hline MARCH & 5.85 & 3.56 & 0.00 & 51.07 & 6.84 & -7.16 & -280 & 0.000 & -7.242 & -3.649 \\
\hline APRIL & 7.89 & 6.16 & 0.00 & 65.80 & 7.05 & -8.79 & -266 & 0.001 & -7.714 & -3.466 \\
\hline MAY & 6.33 & 4.69 & 0.05 & 57.72 & 5.82 & -7.56 & -212 & 0.006 & -7.808 & -2.760 \\
\hline JUNE & 2.79 & 1.82 & 0.00 & 26.10 & 3.09 & -4.29 & -248 & 0.001 & -3.968 & -3.231 \\
\hline
\end{tabular}




\begin{tabular}{|l|l|l|l|l|l|l|l|l|l|l|}
\hline JULY & 2.42 & 1.56 & 0.00 & 27.35 & 2.75 & -3.68 & -304 & 0.000 & -3.600 & -3.963 \\
\hline AUGUST & 3.69 & 2.57 & 0.00 & 24.64 & 3.67 & -6.51 & -318 & 0.000 & -5.991 & -4.146 \\
\hline SEPTEMBER & 4.52 & 3.31 & 0.00 & 56.57 & 4.45 & -5.81 & -256 & 0.001 & -5.350 & -3.335 \\
\hline OCTOBER & 5.92 & 4.35 & 0.00 & 54.56 & 5.79 & -7.73 & -222 & 0.004 & -7.993 & -2.890 \\
\hline NOVEMBER & 6.01 & 4.08 & 0.00 & 48.91 & 6.22 & -4.64 & -186 & 0.016 & -2.420 & -4.890 \\
\hline DECEMBER & 3.63 & 1.68 & 0.00 & 44.61 & 5.31 & -0.97 & -48 & 0.539 & -1.425 & -0.615 \\
\hline Station & 4.54 & 2.79 & 0.00 & 65.80 & 5.43 & -0.44 & -19303 & \multicolumn{1}{l}{$1.87 \mathrm{E}-$} & -0.36 & - \\
\hline ALL & & & & & & & & & & \\
\hline
\end{tabular}

Table 4.2 shows the results of analysis of rainfall data from two stations; one in Buikwe District and Another Station in Mukono District.

\section{Precipitation Station: Mukono}

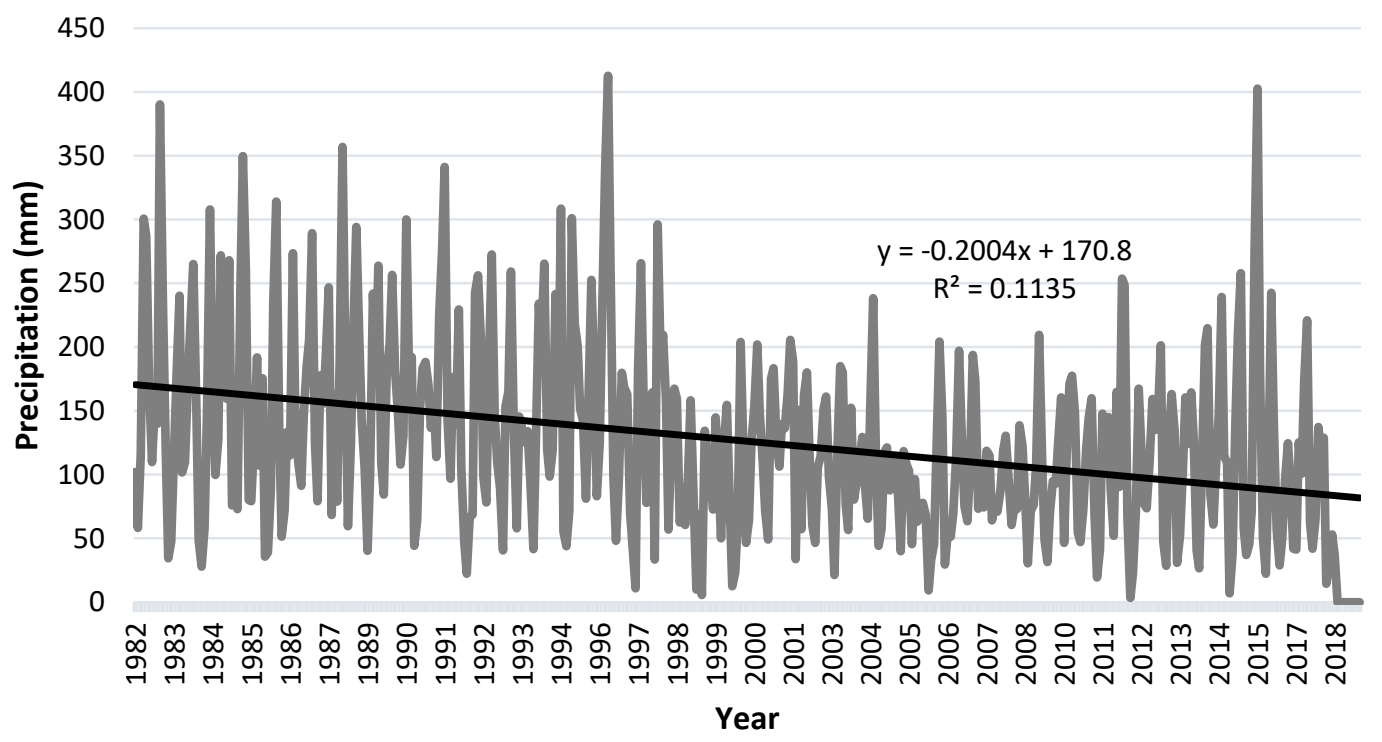

Figure 2: Annual precipitation time series and corresponding interpolated regression line. In this picture, the time series (from 1982 to 2017) is presented.

For a preliminary identification of the time series associated with the yearly changes, a preliminary graphical inspection is highly instructive and meaningful. The annual rainfall time series, averaged over the whole dataset, is illustrated in Figure 2. The corresponding interpolated regression line is also plotted. The variability around the mean value, that is about $29.99 \mathrm{~mm}$, is rather pronounced, despite the smoothing effect induced by the average 
computation over a large area, and a decrease in the annual average rainfall is evident, given the slope of the regression line. The slope of the yearly time series is about $-0.16 \mathrm{~mm} / 35$ years, giving an average estimated annual decrease of about $27.13 \mathrm{~mm}$ in the period 1982-2017. Under the null hypothesis that there exist no trend, the Mann-Kendall trend test is commonly used to determine if a trend exists, and can handle seasonal patterns within the data. The MannKendall test results (shown in table 4.2) indicate that there exists trend (MK $=-18607$, tau = $0.2, \mathrm{P}$-Value $=0.11$ ). The results for trend are not any different even after adjusting for seasonality in the precipitation amounts for the period of study.

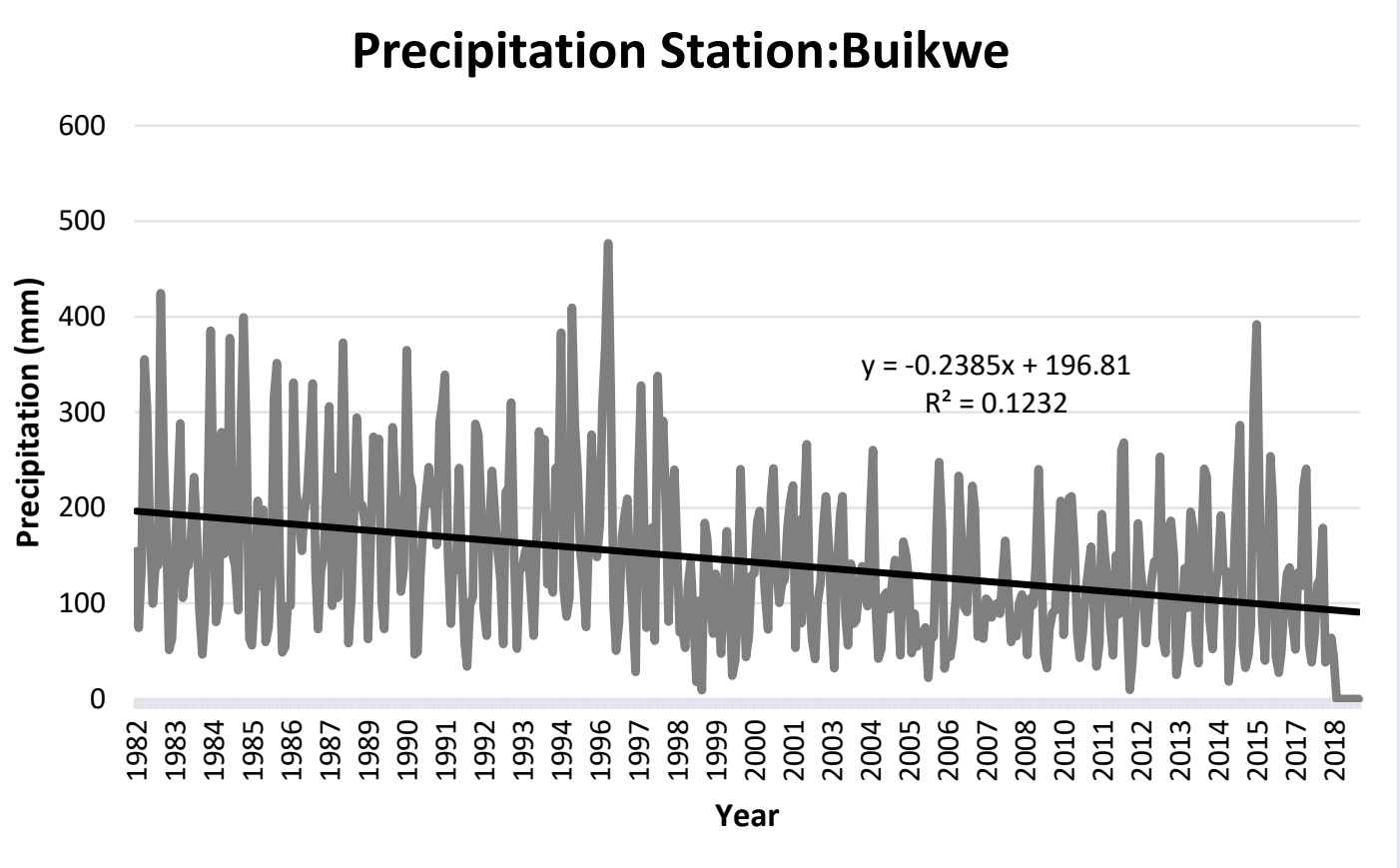

Figure 3: Annual precipitation time series and corresponding interpolated regression line. In this picture, the time series (from 1982 to 2017) is presented.

For a preliminary identification of the time series associated with the yearly changes, a preliminary graphical inspection is highly instructive and meaningful. The annual rainfall time series, averaged over the whole dataset, is illustrated in Figure 3. The corresponding interpolated regression line is also plotted. The variability around the mean value, that is about $28.50 \mathrm{~mm}$, is rather pronounced, despite the smoothing effect induced by the average computation over a large area, and a decrease in the annual average rainfall is evident, given the slope of the regression line. The slope of the yearly time series is about $-0.19 \mathrm{~mm} / 35$ years, giving an average estimated annual decrease of about $27.13 \mathrm{~mm}$ in the period 1982-2017. Under the null hypothesis that there exist no trend, the Mann-Kendall trend test is commonly used to determine if a trend exists, and can handle seasonal patterns within the data. The MannKendall test results (shown in table 4.2) indicate that there exists trend ( $M K=-19767$, tau $=$ 0.21 , P-Value $=0.12$ ). The results for trend are not any different even after adjusting for seasonality in the precipitation amounts for the period of study.

\section{Analysis of all Stations data combined}

When the data from all the stations was added up together to getter the total rainfall in the catchment and trend analysis carried a graph was produced as shown below. 


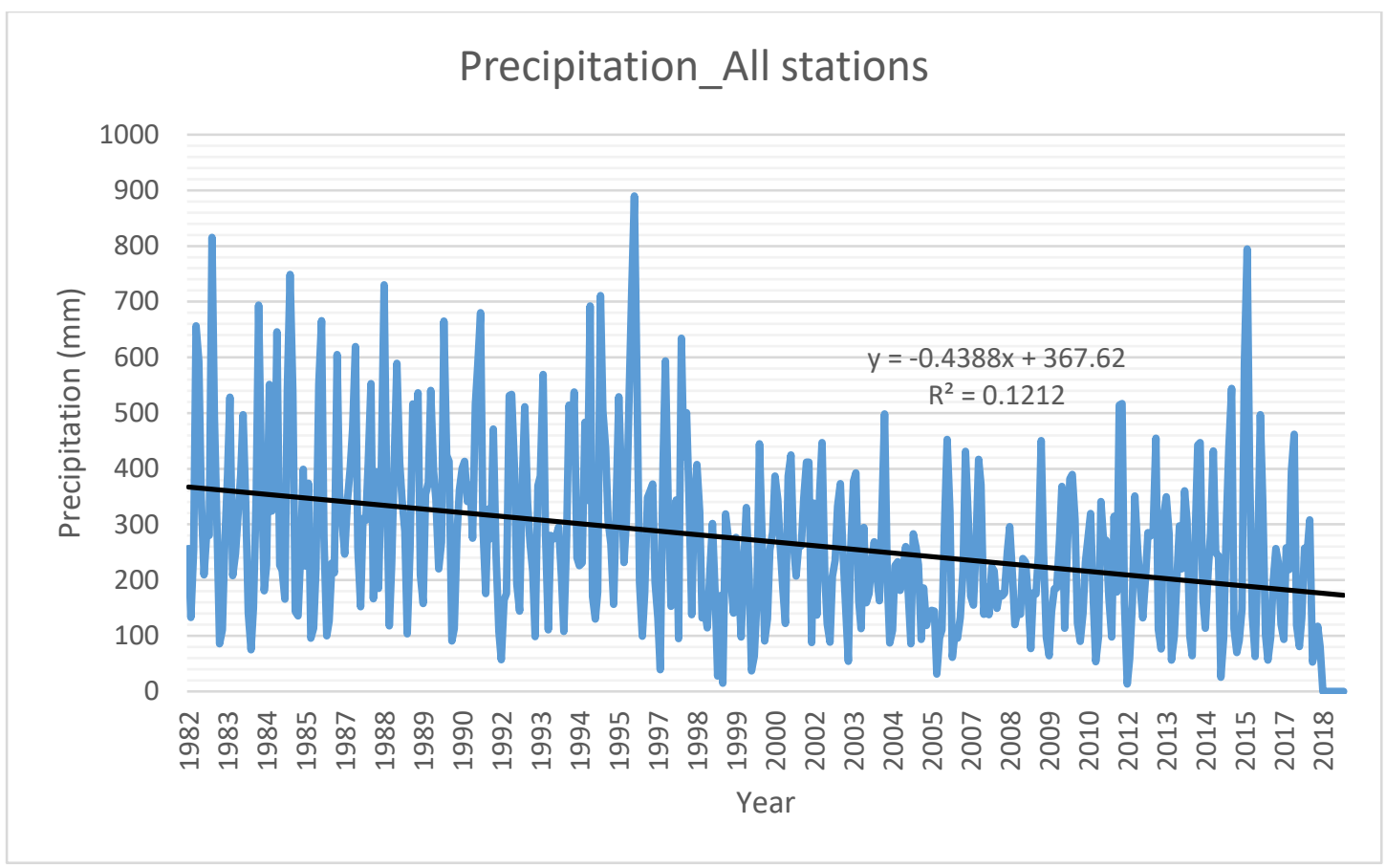

Figure 4: Annual precipitation time series and corresponding interpolated regression line. In this picture, the time series (from 1982 to 2017) is presented.

For a preliminary identification of the time series associated with the yearly changes, a preliminary graphical inspection is highly instructive and meaningful. The annual rainfall time series, averaged over the whole dataset, is illustrated in Figure 3. The corresponding interpolated regression line is also plotted. The variability around the mean value, that is about $29.51 \mathrm{~mm}$, is rather pronounced, despite the smoothing effect induced by the average computation over a large area, and a decrease in the annual average rainfall is evident, given the slope of the regression line. The slope of the yearly time series is about $-0.36 \mathrm{~mm} / 35$ years, giving an average estimated annual decrease of about $54.7743 \mathrm{~mm}$ in the period 1982-2017. Under the null hypothesis that there exist no trend, the Mann-Kendall trend test is commonly used to determine if a trend exists, and can handle seasonal patterns within the data. The MannKendall test results (shown in table 4.2) indicate that there exists trend (MK $=-19303$, tau = $0.2, \mathrm{P}-$ Value $=0.12$ ). The results for trend are not any different even after adjusting for seasonality in the precipitation amounts for the period of study.

The Pettit's test for single change-point detection indicate that change in the trend occurred in the year 1998 ( $K=197$, P-value < 0.05) further indicating that there was a change in the overall rainfall amount. 


\subsection{Conclusion}

The aim of the study was to analyse rainfall and stream flow time series, trend analysis and detect the change points in the River Ssezibwa catchment. The non-parametric Mann - Kendall test was performed for trend analysis and the Petitt's was performed for the single change point detection. The findings indicate that generally the catchment area is experiencing a negative trend in rainfall with an annual decrease of $54.7743 \mathrm{~mm}$. This means that on average since 1982 rainfall depth has been averagely decreasing by $54.7743 \mathrm{~mm}$ every year. This is a serious indicator of climate change effect on the hydrology in this catchment area.

Monthly statistical analysis indicate that all months except December gave a significantly decreasing trend due to values of both Sen's slope and the Z-score. The trend of the whole data on annual daily basis showed also a decreasing trend. The mean annual daily is $4.54 \mathrm{~mm}$ with minimum annual daily rainfall being $2.79 \mathrm{~mm}$ and maximum annual daily rainfall of $65.80 \mathrm{~mm}$ with a standard deviation of $5.43 \mathrm{~mm}$.

However, for the stream flows of River Ssezibwa there has been an average annual increase of $9.4 \mathrm{~m}^{3}$ every year. This increase can be attributed to various factors some of which include the change in land use as a result of many industries and settlement coming up in this catchment area which has led to reduction in vegetation cover hence all runoff from the rains flows in to the river.

The results of the Pettit test show that the change point for rainfall trends is the year 1998 and for the change point for the stream flows is the year 2000. This means that in the years 1998 and 2000 for rainfall and stream flows respectfully is when there was significant changes in the hydrological parameters studied.

Hence based on the results and discussion, this means that there has been an effect on the trends of both stream flows of River Ssezibwa and rainfall amounts in the catchment area. Therefore, there is need to pay critical attention to the hydrological situation in this catchment area. Also in Uganda rainfall is basically a very important climatic variable for agricultural productivity and planning of water resources related projects which the findings of this study important for the planning of water resources development in the catchment area. 


\section{References}

Hemin Sun et al. (2017). Uncertainty Analysis of Hydrological return estimation, taking the upper Yangtze River as an example. Hydrology and Earth System Sciences.

Babu, S. S. (2017). Stochastic time series analysis of hydrology data for water resources. IOP Conference Series: Materials Science and Engineering. IOP Publishing.

Bhardwaj, R. K. (2015). Probability analysis of return period of daily maximum rainfall in annual data set of Ludhiana, Punjab. Punjab Agricultural University, Ludhiana-141 001, India., Department of Soil and Water Engineering. Ludhiana: Indian J. Agric. Research.

Chulsang Yoo et at. (2015). Evaluation of the Concept of Critical Rainfall Duration by Bivariate Frequency Analysis of Annual Maximum Independent Rainfall Event Series in Seoul, Korea. Journal of Hydrologic Engineering.

Donald H. Burn, M. A. (2001). Detection of Hydrologic trends and variability. Journal of Hydrology.

IPCC. (2014). Summary for policymakers. In: ClmateChange2014: Impacts, adaptation, and vulnerability. Part A: Global and sectoral Aspects. Contribution of working group II to the fifth assessment Report of the intergovernmental panel on climate change . Cambridge,United Kingdom: Cambridge University Press.

K. Drapela and I. Drapelova. (2011). Application of Mann-Kendall test and Sen's Slope estimates for trend detection in deposition data from Bily Kriz (Beskydy Mts, the Czech Republic) 1997-2010. Beskydy, 133-146.

Kendall, M. (1955). Rank Correlation Methods. New York: Hafner Publishing.

Meron Teferi Taye, P. W. (2015). Implications of climate change on hydrological extremes in the Blue Nile basin: A review. Journal of Hydrology, elsevier.

Norhan Abd Rahman, F. A. (2016). Frequency Analysis Of Annual Maximum Daily Rainfall in Wadi Alaqiq, Saudi Arabia. Taibah University, Department of Civil Engineering. Johor, Malaysia: Malaysian Journal of Civil Engineering.

UBOS. (2017). Statistical Abstract 2017. Uganda Bureau of Statistics. Retrieved from https://www.ubos.org,publications, 03

Yenigu et al. (2016). Investigation of The Maximum Flow Trends and. Applied Ecology And Environmental Research, 589-606. 